\title{
Avaliação de textos acadêmicos escritos: uma perspectiva enunciativa
}

Carolina Knack*

Giovane Fernandes Oliveira**

\section{Resumo}

Este trabalho tem como objetivo propor uma perspectiva enunciativa de avaliação de textos acadêmicos escritos em contexto de ensino-aprendizagem de língua materna na Universidade. Em um primeiro momento, valendo-se de pressupostos da Teoria da Enunciação de Émile Benveniste, apresenta: a) uma concepção de avaliação como ato de enunciação; b) o funcionamento enunciativo das instâncias de avaliação professor-aluno, aluno-aluno e autoavaliação; c) princípios teórico-metodológicos para a avaliação que consideram a cultura, a intersubjetividade, a situação criadora de referência, os instrumentos linguísticos de realização da enunciação e os planos global e analítico de análise enunciativa do texto. Em um segundo momento, desloca esses elementos para a composição de uma grade de avaliação do texto acadêmico escrito.

Palavras-chave: Avaliação. Enunciação. Escrita acadêmica.

\section{Introdução}

Se hoje já não se pode dizer que são escassas as pesquisas sobre o ensino-aprendizagem de língua materna na Universidade, devido ao crescente número de estudos sobre esse tema no país, pode-se ainda afirmar que a avaliação permanece um dos aspectos menos investigados no processo de letramento acadêmico. Pode-se afirmar também que a avaliação é, em sala de aula, ainda

\footnotetext{
Professora Adjunta do Instituto de Letras e Artes (ILA) da Universidade Federal do Rio Grande (Furg). Doutora e Mestra em Estudos da Linguagem, na linha de pesquisa Análises Textuais, Discursivas e Enunciativas, pelo Programa de Pós-Graduação em Letras da Universidade Federal do Rio Grande do Sul (Ufrgs). Especialista em Estudos Linguísticos do Texto (Ufrgs). Graduada em Licenciatura em Letras (Ufrgs). E-mail: carolinaknack@furg.br

** Mestrando em Estudos da Linguagem, na linha de pesquisa Análises Textuais, Discursivas e Enunciativas, pelo Programa de Pós-Graduação em Letras da Universidade Federal do Rio Grande do Sul (Ufrgs). Graduado em Licenciatura em Letras (Ufrgs). E-mail: giovane.oliveira@ufrgs.br
}

Data de submissão: set. 2017 - Data de aceite: out. 2017 http://dx.doi.org/10.5335/rdes.v13i3.7407 
um dos aspectos menos discutidos pelo professor com os alunos: embora sejam frequentemente avaliados em função dos textos que produzem, os estudantes nem sempre têm conhecimento dos parâmetros que orientam essa avaliação. Por isso, a avaliação de textos acadêmicos tem sido alvo de críticas dos Estudos dos Letramentos Acadêmicos, os quais contestam a abordagem tradicional da escrita na Universidade por esta promover o que denominam de práticas institucionais do mistério. Para Lillis (1999), a distância entre as expectativas dos professores em relação aos textos dos alunos e a compreensão desses de tais expectativas, bem como das normas que regem a escrita acadêmica, deriva de uma não explicitação dessas expectativas e dessas normas. Segundo a autora, a ausência de instruções explícitas parece resultar de uma espécie de crença dos docentes na clareza das formas de funcionamento dos textos acadêmicos, como se as convenções a eles subjacentes fossem já conhecidas pelos discentes, o que caracterizaria o ensino e a avaliação da escrita na Universidade como práticas do mistério.

Os modos tácitos de ensinar e avaliar textos acadêmicos parecem-nos ser consequências da institucionalização das práticas do mistério. Esses modos tácitos traduzem-se não apenas no desconhecimento dos estudantes acerca do que é deles esperado em termos de leitura e de escrita, mas também na sua incompreensão dos parâmetros a partir dos quais suas produções textuais são avaliadas, parâmetros esses, em geral, não compartilhados com os alunos. Acreditamos, com Simões et al. (2012, p. 127), que a avaliação é parte integrante do processo de ensino-aprendizagem e, como tal, atividade "processual, contínua e sinalizadora de que a responsabilidade pela aprendizagem é compartilhada por todos na sala de aula".

Tal abordagem avaliativa inscreve-se no chamado paradigma emergente de avaliação, distinto do paradigma tradicional. Esses dois grandes modelos teóricos são confrontados por Suassuna (2006), segundo a qual, o primeiro caracteriza-se por uma avaliação somativa, centrada no aluno e no produto do ensino-aprendizagem, enquanto o segundo caracteriza-se por uma avaliação formativa, que desloca a ênfase do produto para o processo de ensino-aprendizagem e avalia, além do aluno, o professor, questionando a ação docente em termos de estratégias didáticas, conteúdos curriculares, objetivos específicos tanto do componente curricular quanto de cada tarefa. A avaliação formativa não tem apenas função classificatória, limitada à atribuição de uma nota, conceito ou parecer: trata-se antes de uma ferramenta pedagógica com função diagnóstica e reguladora, que indica o que já foi alcançado e o que ainda pode ser aprimorado (LUCKESI, 1996). Conforme Suassuna (2006), a perspectiva formativa destaca a dimensão discursiva da avaliação, tomada como uma rede de sentidos a 
serem interpretados e analisados em busca do aperfeiçoamento das condições de ensino-aprendizagem, de forma que os resultados da avaliação deixam de ser definitivos e inquestionáveis e passam a ser índices para compreender e agir.

Adotar os princípios da avaliação formativa implica reconhecer a autonomia do aluno para avaliar a sua aprendizagem e a do outro e a necessidade de diversificar as técnicas e os instrumentos avaliativos, como a autoavaliação e a avaliação entre colegas a partir de grades, que caminham na direção de uma prática avaliativa menos misteriosa e mais intersubjetiva. A busca pela intersubjetividade na avaliação de textos acadêmicos justifica a opção pela Teoria da Enunciação de Émile Benveniste como aporte teórico deste estudo. Segundo Benveniste, em $O$ aparelho formal da enunciação (1970/2006), "Enquanto realização individual, a enunciação pode se definir, em relação à língua, como um processo de apropriação", mas, desde que o locutor se apropria da língua, "ele implanta o outro diante de si, qualquer que seja o grau de presença que ele atribua a este outro" (BENVENISTE, 1970/2006, p. 84, grifo do autor). Nesse sentido, toda enunciação é uma alocução, porque sempre pressupõe um locutor e um alocutário, que constituem juntos a estrutura do diálogo e alternam o protagonismo da enunciação a cada tomada de palavra. A intersubjetividade é, pois, a condição da linguagem e da enunciação e, portanto, deve ser um princípio orientador das práticas discursivas em sala de aula.
Essa leitura propositiva que coloca em relação a Teoria da Enunciação e o contexto de ensino-aprendizagem de língua materna sustenta-se no fato de que essa teoria - não proposta por Benveniste como um "modelo", tal como a Linguística costuma compreender a palavra "modelo" (FLORES et al., 2008) - constitui-se de reflexões sobre a presença do homem na língua (FLORES, 2012). Neste artigo, a leitura singular que empreendemos acerca das bases enunciativas que o sintagma o homem na lingua ${ }^{1}$ subsume tem uma finalidade: 0 deslocamento de tais pressupostos para a abordagem de nosso objeto, o texto acadêmico escrito e sua avaliação.

Assim, considerando que enunciar consiste em converter a língua em discurso e implantar o outro diante de si, este estudo propõe-se a responder à seguinte questão: como avaliar textos acadêmicos escritos numa perspectiva enunciativa que leva em conta menos a regularidade e mais a singularidade do processo de produção textual acadêmica e das relações intersubjetivas que o constituem? Desse interrogante, deriva o objetivo geral deste trabalho: propor uma perspectiva enunciativa de avaliação de textos acadêmicos escritos.

Para responder à questão e atingir o objetivo elencado, organizamos o artigo do seguinte modo: primeiramente, desenvolvemos um referencial teórico-metodológico para subsidiar a avaliação de textos acadêmicos escritos, a partir da proposição de uma concepção de avaliação como ato de enunciação e de 
instâncias e princípios enunciativos para a avaliação; em seguida, empreendemos o deslocamento desse referencial para a elaboração de uma grade avaliativa; por fim, concluímos com as contribuições esperadas da proposta apresentada.

\section{A Teoria da Enunciação de Émile Benveniste:} bases para a elaboração de uma proposta enunciativa de avaliação de textos acadêmicos escritos

Nossa proposição de um construto para a avaliação de textos acadêmicos escritos sustenta-se em uma perspectiva enunciativa de estudo da linguagem, especificamente na Teoria da Enunciação de Émile Benveniste, cujos pressupostos podem ser unificados no a priori o homem na língua (FLORES, 2012). Se, como explica Flores (2012), o homem está na língua, é porque ele é fundado simbolicamente na linguagem. É Benveniste quem esclarece esse princípio:

[...] não atingimos nunca o homem separado da linguagem e não o vemos nunca inventando-a. Não atingimos jamais o homem reduzido a si mesmo e procurando conceber a existência do outro. É um homem falando que encontramos no mundo, um homem falando com outro homem, e a linguagem ensina a própria definição de homem (BENVENISTE, 1958/2005, p. 285).

Assim como encontramos no mundo um homem falando com outro homem,
[...] é um homem escrevendo que encontramos no mundo, um homem escrevendo para outro homem; também é um homem lendo que encontramos no mundo, um homem lendo o que outro escreveu (SILVA, 2015, p. 17).

E acrescentaríamos: é um homem avaliando o que outro falou ou escreveu. Logo, para constituir-se subjetivamente na linguagem, um está na dependência do outro, que lhe concede um lugar de enunciação e o significa. Dessa maneira, o conceito de intersubjetividade, pilar da reflexão enunciativa benvenistiana, também é o pilar de nossa proposta pedagógica de avaliação da produção textual acadêmica escrita. Além desse, outros conceitos sustentam nossa proposição, sendo deslocados para o contexto de ensino-aprendizagem de língua materna. Para deles tratar, é preciso, antes, estabelecer alguns critérios de seleção e leitura dos textos benvenistianos.

Isso porque, como explica Flores (2013), a amplitude da obra de Émile Benveniste - que ultrapassa o campo dos estudos enunciativos - exige a delimitação de um ponto de vista de leitura que direcione a incursão nessa obra, motivo pelo qual defende o estabelecimento de um corpus textual de referência que se constitua como o conjunto de textos a serem pesquisados. Levando em conta essas orientações e os propósitos deste artigo, definimos o nosso corpus textual de pesquisa circunscrevendo-nos à visada enunciativa do pensamento benvenistiano e elegemos, para recuperar as bases dessa visada, dois textos integrantes de Problemas de Linguística Geral II e I, 
respectivamente: $O$ aparelho formal $d a$ enunciação (1970/2006), artigo em que o linguista reúne os fundamentos do(s) conceito(s) de enunciação, e Vista d'olhos sobre o desenvolvimento da linguística (1963/2005), artigo em que delineia concepções de cultura, as quais são relevantes para propormos uma abordagem de avaliação das práticas sociais letradas.

Com base nesses artigos, sintetizamos, a seguir, os fundamentos teóricos que podem ser deslocados para a formulação de uma concepção enunciativa de avaliação.

\section{Fundamentos para a proposição de uma concepção enunciativa de avaliação de textos acadêmicos escritos}

O título que damos a esta seção antecipa o ponto de chegada de nossa reflexão: concebemos a avaliação como um ato enunciativo. Esse entendimento ancora-se na nossa leitura do artigo $O$ aparelho formal da enunciação (1970/2006), texto em que Benveniste, além de elaborar e sintetizar aspectos da teoria enunciativa, a abre para um programa futuro (NORMAND, 1996), sinalizando a necessidade de distinguir a enunciação falada da enunciação escrita e afirmando que "Amplas perspectivas se abrem para a análise das formas formas complexas do discurso" a partir do quadro que ele esboçou (BENVENISTE, 1970/2006, p. 90).

Entendemos que essas possibilidades devem partir da consideração da enunciação como ato individual de utilização da língua que a coloca em funcionamento, tal como definido pelo mestre enunciativo. Essa mobilização da língua pelo locutor dá-se em vista do outro - seja este outro real, imaginado, implícito, explícito, individual, coletivo-, na medida em que, segundo Benveniste, toda enunciação é uma alocução. Por isso, $o$ autor destaca que "O que em geral caracteriza a enunciação é a acentuação da relação discursiva com o parceiro [...]" (BENVENISTE, 1970/2006, p. 87, grifos do autor). Essa condição intersubjetiva da linguagem é marcada pela estrutura do diálogo, a qual instaura o que o linguista denomina de quadro figurativo da enunciação, uma vez que a enunciação propõe duas figuras necessárias que, na posição de parceiros, são, de modo alternado, protagonistas da enunciação. A condição da mobilização da língua está, portanto, vinculada à necessidade de expressar uma relação com o mundo, isto é, de o locutor referir pelo discurso e de o alocutário co-referir (BENVENISTE, 1970/2006).

Assim, pelo princípio da intersubjetividade, o locutor, ao enunciar, faz sua passagem a sujeito e, dessa maneira, constitui-se em uma posição na linguagem $^{2}$, ocupando um lugar de enunciação. Essa posição de locutor assinalada no discurso está atrelada a uma textura de 
circunstâncias que determina os modos de enunciação (KNACK, 2016b).

Compreendemos que tais propriedades caracterizam o fenômeno geral da enunciação (BENVENISTE, 1970/2006). Esse fenômeno geral, segundo Knack (2012), pode ser concebido em termos de especificidade: partindo da indicação de Benveniste de que seria necessário distinguir a enunciação falada da enunciação escrita, a autora concebe esses como fenômenos específicos da enunciação. Após caracterizar o funcionamento enunciativo de ambas as modalidades, a autora desloca essa reflexão para o contexto de ensino-aprendizagem de língua materna e propõe uma noção geral para texto e noções específicas para texto falado e escrito, sendo a última a que nos interessa neste momento, na medida em que buscamos propor parâmetros para a avaliação da produção textual acadêmica escrita:

Considerando os pressupostos enunciativos, podemos conceber a escrita como um ato enunciativo e o texto escrito como aquilo que resulta desse ato. Portanto, podemos definir o texto escrito como o resultado de um processo de produção intersubjetiva entre locutores situados em tempo e espaço distintos, condensando o ato de enunciação e o produto deste, cuja materialidade, de extensão não delimitada, apresenta por escrito as marcas que permitem ao alocutário re-constituir os sentidos atualizados em formas pelo locutor (KNACK, 2012, p. 159, grifos da autora).

Essa ideia de re-constituição, tomada de Naujorks (2011), convoca a ideia benvenistiana de que a enunciação escrita situa-se em dois planos: "o que escreve se enuncia ao escrever e, no interior de sua escrita, ele faz os indivíduos se enunciarem." (BENVENISTE, 1970/2006, p. 90). Entendemos esses dois planos como o aqui-agora da escrita propriamente dita e o aqui-agora da leitura. "Pela leitura, o alocutário (o tu pressuposto na escrita, agora eu-leitor) depara-se com referências instauradas pelo locutor (antes o eu-escritor) e, a partir do engendramento forma-sentido no texto escrito, busca re-constituir os sentidos que aquele que escreveu buscou atualizar" (KNACK, 2016b, p. 85, grifos da autora). Nessa direção, também a leitura é um ato enunciativo. E essa é, sobretudo, a tese de Naujorks (2011, p. 49), que compreende a leitura como "um fazer de novo, um processo de (re)significação, ou seja, fazer de novo o percurso da significação" instaurado no texto.

A partir das reflexões enunciativas sobre texto escrito (KNACK, 2012) e leitura (NAUJORKS, 2011) e também da conclusão de $O$ aparelho formal da enunciação (1970/2006), em que Benveniste parece inserir a enunciação escrita dentre as ditas formas complexas do discurso a serem estudadas no contexto da enunciação, Oliveira (2016) propõe uma concepção enunciativa de escrita acadêmica ${ }^{3}$. Segundo o autor, "a escrita acadêmica, mais do que um conjunto de técnicas de redação, revela-se como uma forma complexa de um discurso institucionalizado" (OLIVEIRA, 2016, p. 95, grifos do autor). $\mathrm{O}$ caráter institucional da escrita acadêmica deve-se à sua vinculação à instituição universitária e à constituição 
dos distintos campos do saber, os quais produziram, historicamente, não apenas conhecimentos disciplinares específicos como também convenções escriturais igualmente específicas na veiculação desses conhecimentos. Assim, Oliveira (2016) concebe a escrita acadêmica como

[...] uma forma complexa do discurso letrado desdobrada em dois planos enunciativos distintos: o plano da produção escrita, que requer do locutor-escrevente a apropriação dos conhecimentos disciplinares e das convenções escriturais próprias ao seu campo do saber, bem como o desprendimento da riqueza contextual no processo de conversão da língua em discurso escrito; e o plano da leitura, que requer também do locutor-leitor a apropriação dos conhecimentos disciplinares e das convenções escriturais próprias ao seu campo do saber, para que possa transitar entre conceitos teóricos e re-constituir as referências produzidas pelo locutor-escrevente a partir do sentido atualizado em formas no texto escrito (OLIVEIRA, 2016, p. 97, grifos do autor).

Valendo-nos desses fundamentos e os deslocando para o contexto de ensino-aprendizagem de língua materna, postulamos que também a avaliação é um ato enunciativo. Isso porque compreendemos que o locutor, ao se colocar na posição de locutor-avaliador, empreende $o$ ato enunciativo de leitura de um texto escrito; estabelece, assim, um alocutário, ainda que este seja um desdobramento de si mesmo, e, consequentemente, apropria-se da língua para produzir uma enunciação de retorno ${ }^{4}$, que pode ser falada ou escrita, a esse alocutário que lhe convocou a ocupar tal posição. Dessa maneira, entendemos que a avaliação é um duplo ato enunciativo; duplo porque considera dois movimentos: o da leitura do texto escrito e o da enunciação falada ou escrita que produz um texto de retorno. Em nossa proposta, privilegiamos a enunciação de retorno escrita. $\mathrm{E}$ a que esta se propõe? Ora, compreendemos que $o$ ato enunciativo de avaliação atua na direção de possibilitar a re-significação dos modos de enunciação pelos quais o aluno converte a língua em discurso e se propõe como sujeito do seu dizer no espaço acadêmico, cujas especificidades serão abordadas junto aos princípios enunciativos para a avaliação.

Esse breve percurso conduz-nos à formulação da seguinte concepção enunciativa de avaliação: a avaliação de textos acadêmicos escritos é um duplo ato enunciativo de leitura e de escrita que produz uma enunciação de retorno a uma outra enunciação para promover a re-significação dos modos de enunciação do alocutário e que se constitui pela ocupação de uma diferente posição de locutor-avaliador a cada diferente instância avaliativa.

$\mathrm{O}$ funcionamento enunciativo de tais instâncias avaliativas é descrito a seguir.

\section{Instâncias enunciativas de avaliação de textos acadêmicos escritos}

Chamamos instâncias enunciativas de avaliação as distintas relações intersubjetivas constituídas em atos de avaliação: a instância de avaliação professor-aluno, a instância de avaliação 
aluno-aluno e a instância de autoavaliação $o^{5}$. Essas instâncias comportam diferentes modos de avaliar, os quais impõem uma distinção entre técnicas de avaliação e instrumentos de avaliação.

A esse respeito, Haydt esclarece: "A técnica de avaliação é o método de se obter as informações desejadas. $\mathrm{O}$ instrumento de avaliação é o recurso que será usado para isso" (HAYDT, 2004, p. 56 apud FURTOSO, 2008, p. 143). Aproximando a proposta da autora da nossa, a técnica avaliativa consiste no método que define cada instância enunciativa de avaliação: a avaliação professor-aluno é a técnica definidora da primeira instância; a avaliação aluno-aluno é a técnica definidora da segunda instância; a autoavaliação é a técnica definidora da terceira instância. Isso não significa, porém, que as instâncias (relações) se reduzam às técnicas (métodos), mas que essas são os mecanismos estruturantes daquelas. Já o instrumento avaliativo não se confunde com a técnica metodológica, mas diz respeito ao procedimento que a operacionaliza, ou seja, o recurso material que torna $o$ ato de avaliação concretizável numa dada instância enunciativa. Nosso instrumento de referência é a grade de avaliação, que apresentaremos adiante. Por ora, buscaremos caracterizar as instâncias enunciativas de avaliação.

A instância professor-aluno implica uma avaliação assimétrica, pois, embora professor e aluno sejam ambos locutores que se apropriam da língua para se enunciarem como sujeitos, quando, na estrutura do diálogo avaliativo, o professor ocupa a posição de locutor-avaliador e o aluno a de alocutário-avaliado, institui-se entre eles uma relação em nada simétrica, tanto em termos enunciativos quanto em termos culturais.

Em termos enunciativos, a avaliação do texto do aluno pelo professor é assimétrica, porque é o professor o protagonista da enunciação e aquele que, de alocutário-leitor convocado pelo locutor-aluno a ler o seu texto escrito, passa a locutor-avaliador que produz uma enunciação de retorno por meio da qual convoca esse locutor-aluno, agora alocutário-avaliado, a retomar sua posição de locutor para ressignificar seus modos de enunciação na reescrita de seu texto. A assimetria dos papéis, aqui, deve-se à temporalidade enunciativa, que não é senão "o presente inerente à enunciação, que se renova a cada produção de discurso" (BENVENISTE, 1970/2006, p. 84) e que se determina em relação ao aqui-agora do locutor ${ }^{6}$. Assim, a avaliação professor-aluno é enunciativamente assimétrica, pois o protagonismo da enunciação é exercido apenas pelo professor, centro de referência interno dessa instância.

Em termos culturais, a assimetria da avaliação empreendida pelo professor deve-se ao fato de ser este o interlocutor primeiro do aluno na Universidade, visto por ele como uma figura autorizada a ajustar os seus usos da língua às expectativas culturais acadêmicas. Nesse sentido, o professor assume "a 
representação da cultura, da instituição social, do saber, da leitura e da avaliação, e por isso mesmo representa para o aluno um poder dizer, um poder mostrar-se de locutor através do texto escrito" (JUCHEM, 2012, p. 115, grifos da autora). A avaliação professor-aluno, portanto, é culturalmente assimétrica, na medida em que a ressignificação pelo aluno dos seus modos de enunciação, nesta instância, está na dependência da enunciação de retorno do professor, representante da cultura acadêmica e, por isso, o indicador por excelência dos caminhos a serem percorridos em busca de tal re-significação.

Contudo, não somente o professor pode assumir a posição de locutor-avaliador do texto do aluno, mas também o colega pode fazê-lo. Nesse caso, embora permaneça a assimetria enunciativa decorrente da transcendência temporal do $e u$ em relação ao tu no presente da enunciação, a assimetria cultural desvanece em face do estatuto social compartilhado entre os alunos. Knack (2016b) vincula o estatuto social do falante à posição por ele ocupada na sociedade, defendendo que a passagem de uma posição social à outra altera o seu estatuto social e pode provocar mudanças na sua relação com a língua e, consequentemente, na posição de locutor por ele assumida ao enunciar. Deslocando a tese da autora para o contexto deste artigo, diríamos que também a ocupação de uma mesma posição na sociedade que o outro da alocução e, por conseguinte, o compartilhamento de um mesmo estatuto social com esse outro podem provocar mudanças na relação do locutor com a língua.

Isso porque, na Universidade, os alunos ocupam uma mesma posição social, a de estudantes universitários, do que resulta a simetria cultural que distingue esta instância. Nessa perspectiva, ainda que ocupem posições distintas no quadro figurativo da avaliação, um aluno como locutor-avaliador e outro como alocutário-avaliado, por compartilharem um mesmo estatuto social, tal avaliação constitui-se uma avaliação entre pares. Nessa avaliação socializada, o locutor-aluno (eu) convoca o alocutário-colega $(t u)$ a ler o seu texto escrito e a assumir a posição de locutor-avaliador (antes $t u$, agora $e u$ ), na qual o implanta como alocutário-avaliado (antes $e u$, agora $t u$ ) e produz uma enunciação de retorno à sua enunciação anterior, convocando-o a reassumir a posição de locutor para $r e$-significar seus modos de enunciação a partir dessa enunciação de retorno. Dessa maneira, ambos referem e co-referem no processo intersubjetivo que possibilita, ao avaliado, a ressignificação dos seus modos de enunciação na reescrita de seu texto e, ao avaliador, a ressignificação dos seus modos de enunciação na leitura avaliativa do texto do primeiro. A avaliação aluno-aluno contribui, pois, para o desenvolvimento das competências de leitura e escrita dos alunos, tornando-lhes as práticas letradas acadêmicas mais significativas, porque situadas em propostas interlocutivas de estudo do texto. 
Essa interlocução é redimensionada na instância de autoavaliação. Como no monólogo, concebido por Benveniste como uma variedade do diálogo, "um diálogo interiorizado, [...] entre um eu locutor e um eu ouvinte" (BENVENISTE, 1970/2006, p. 88$)^{7}$, na autoavaliação, parece haver um desdobramento do eu, em que o aluno ocupa as duas posições do quadro figurativo, a de locutor-avaliador e a de alocutário-avaliado. A ocupação simultânea desses dois lugares de enunciação exige dele um deslocamento da posição de interlocutor do ato de avaliação para a de protagonista desse ato e, ao mesmo tempo, a manutenção da posição de interlocutor para poder avaliar o seu próprio texto. Essa autoavaliação obriga um exercício de distanciamento, o qual faz dela um diálogo interiorizado, entre um eu leitor e um eu escrevente. A constituição desse diálogo interiorizado implica a passagem da condição de falante ${ }^{8}$ à condição de analista de linguagem (FARIAS, 2016).

Para Farias (2016), além do pesquisador, o professor e o aluno acedem igualmente à condição de analistas de linguagem, quando se voltam para os seus usos da língua com um olhar investigativo, que requer "um esforço do analista para 'sair de si' e de seu lugar para atingir o lugar do outro" (FARIAS, 2016, p. 114). Essa experiência de análise, porém, é sempre determinada pela sua experiência de fala (e de escrita): "O lugar do analista de linguagem, portanto, é duplamente instanciado: o analista faz uso da língua, como falante [e escrevente], para retornar a ela mesma, como analista" (FARIAS, 2016 , p. 117, acréscimo nosso). No ato de autoavaliação, o aluno constitui-se locutor-avaliador ao distanciar-se do seu texto para lê-lo como leria a produção textual de outrem, para lê-lo como um analista de linguagem. Nesse gesto de distanciamento, implanta a si mesmo como alocutário-avaliado e se volta sobre a sua própria enunciação para analisar como, por meio dela, o sentido se forma em palavras em seu texto. Se, nas duas instâncias enunciativas de avaliação anteriores, a ressignificação dos seus modos de enunciação dependia da enunciação de retorno do outro da alocução, nesta, tal ressignificação não depende senão dele próprio, que produz a enunciação de retorno por meio da qual orienta a si mesmo na reescrita de seu texto.

Todas e cada uma das três instâncias de avaliação, apresentadas nesta seção, realçam o diálogo intersubjetivo em cuja base reside a função mediadora da língua. No ato enunciativo de avaliação, a ressignificação dos modos de enunciação do alocutário-avaliado está condicionada à enunciação de retorno produzida pelo locutor-avaliador, que orienta a reorganização dessas formas no texto avaliado em vista do aprimoramento dos sentidos. Entretanto, a qualidade textual adquirida pela produção do aluno na reescrita orientada pela avaliação é apenas um efeito a curto prazo das instâncias avaliativas, que se revestem de potencial pedagógico, sobretudo, por seus efeitos a longo prazo: enquanto a instância de 
avaliação professor-aluno dá ênfase à constituição do aluno como produtor de textos, a instância de avaliação aluno-aluno e a instância de autoavaliação dão ênfase à sua constituição como produtor de textos e também como leitor do texto do outro e do seu próprio. O desdobramento da avaliação de textos acadêmicos escritos nessas três instâncias enunciativas figura, pois, como um imperativo no ensino-aprendizagem de língua materna na Universidade.

A concepção e as instâncias enunciativas de avaliação, elaboradas anteriormente, levam-nos a interrogar: com base em que pressupostos esse processo de avaliação pode instaurar-se? Com 0 objetivo de responder a tal pergunta, propomos, a seguir, cinco princípios teórico-metodológicos para a avaliação de textos acadêmicos escritos numa perspectiva enunciativa.

\section{Princípios enunciativos para a avaliação de textos acadêmicos escritos}

A proposição dos princípios para a avaliação de textos acadêmicos escritos parte de um "caminho metodológico" delineado por Benveniste em $O$ aparelho formal da enunciação (1970/2006, p. 83): "Na enunciação consideraremos, sucessivamente, o próprio ato, as situações em que ele se realiza, os instrumentos de sua realização." Entendemos que esses três elementos (ato, situação e instrumentos), interdependentes na enunciação, geram cada qual um princípio enunciativo para a avaliação de textos acadêmicos.

Porém, compreendemos que esses princípios se submeteriam, primeiro, a um outro, de natureza englobante, cujo cerne repousa na cultura. Segundo Benveniste (1963/2005), o homem, ao nascer, nasce no seio de uma cultura e, com a língua, aprende os rudimentos dessa cultura. Assim, no contexto de ensino-aprendizagem de língua materna na Universidade, o aluno, ao apropriar-se da língua para enunciar e produzir seu texto acadêmico escrito, apropria-se não só de formas da língua, mas também de valores culturais que regem os modos de constituir os textos nesse espaço de interlocução. A instauração do aluno como leitor e escrevente de textos acadêmicos passa pelo "[...] reconhecimento e [pela] compreensão dos preceitos que regem a prática de pesquisa e de uso da língua em sua área” (KNACK, 2016a, p. 96). É Benveniste quem nos permite atrelar as convenções escriturais, no dizer de Oliveira (2016), ou os modos de enunciação, no dizer de Knack (2016b), à cultura, na medida em que o linguista enunciativo assim a conceitua em Vista d'olhos sobre o desenvolvimento da linguística (1963/2005):

A cultura define-se como um conjunto muito complexo de representações, organizadas por um código de relações e de valores: tradições, religião, leis, política, ética, artes, tudo isso de que o homem, onde quer que nasça, será impregnado no mais profundo da sua consciência, e que dirigirá o seu comportamento em todas as formas da sua atividade [...] (BENVENISTE, 1963/2005, p. 32). 
Esse conjunto de representações e valores que dirige o comportamento do homem em suas atividades, incluindo os modos de produzir textos acadêmicos, deve ser considerado quando da avaliação do texto do aluno, uma vez que esta integra "[...] as atividades que versam sobre sua língua materna [que] podem ampará-lo a compreender e a (re)significar os diferentes espaços de enunciação nos quais converte a língua em discurso e se propõe como sujeito do seu dizer" no universo acadêmico (KNACK, 2016a, p. 97).

Assim, o primeiro princípio postula que a avaliação de textos acadêmicos considera a cultura acadêmica como um conjunto de valores que rege os modos de enunciação no universo acadêmico.

Tal conversão da língua em discurso encaminha a refletirmos acerca do ato de enunciação. Ao conceber que a enunciação é ato que coloca a língua em funcionamento, Benveniste (1970/2006, p. 87) atenta para o fato de que há "duas 'figuras' igualmente necessárias, uma, origem, a outra, fim da enunciação." Portanto, a noção de ato coloca em relevo a intersubjetividade, condição para o locutor (eu) constituir-se como tal em vista de um alocutário $(t u)$. Isso significa que, ao avaliar o texto acadêmico escrito, as relações intersubjetivas que o constituem devem ser examinadas, pois o aluno apropria-se da língua para enunciar sua posição de locutor em vista de um alocutário previsto como leitor de seu texto; assim, engendra determinadas formas da língua (e não outras) para constituir sentidos em determinada situação de discurso. Logo, o segundo princípio enunciativo postula que $a$ avaliação de textos acadêmicos considera a intersubjetividade constitutiva da conversão da língua em discurso pelo aluno.

Dessa maneira, o ato de enunciação implica os demais elementos constitutivos do quadro formal: a situação e os instrumentos, motivo pelo qual os dois próximos princípios abarcam tais elementos. Segundo Benveniste (1970/2006, p. 84), a condição mesma de mobilização e de apropriação da língua "[...] é, para o locutor, a necessidade de referir pelo discurso, e, para o outro, a possibilidade de co-referir identicamente, no consenso pragmático que faz de cada locutor um co-locutor." Assim, "a língua se acha empregada para a expressão de uma certa relação com o mundo" (BENVENISTE, 1970/2006, p. 84). Essa relação não preexiste à enunciação: ela é construída discursivamente e, também, provocada discursivamente. Benveniste (1970/2006, p. 84) mesmo salienta: "A referência é parte integrante da enunciação". Portanto, vinculada à intersubjetividade e ancorada na situação enunciativa, a construção da referência é uma atividade discursiva e é como realidade discursiva que deve ser levada em conta na avaliação do texto. Em vista disso, o terceiro princípio enunciativo postula que $a$ avaliação de textos acadêmicos considera a situação criadora de referência 
para o aluno expressar sua relação com o mundo.

Para "expressar" sua relação com o mundo, é preciso "O locutor se apropria[r] do aparelho formal da língua e enuncia[r] sua posição de locutor por meio de índices específicos, de um lado, e por meio de procedimentos acessórios, de outro" (BENVENISTE, 1970/2006, p. 84). Esse jogo de formas específicas, que coloca o "locutor em relação constante e necessária com sua enunciação", abarca os índices específicos (categorias de pessoa, tempo e espaço) e os procedimentos acessórios de engendramento de tais formas para a constituição do sentido no texto. Como o emprego da língua é "[...] um mecanismo total e constante que, de uma maneira ou de outra, afeta a língua inteira" (BENVENISTE, 1970/2006, p. 82), a avaliação do texto acadêmico escrito deve levar em conta o sentido singular que decorre da articulação dessas formas. Por isso, o quarto princípio postula que a avaliação de textos acadêmicos considera a imbricação entre forma e sentido resultante da atualização pelo aluno dos índices específicos e dos procedimentos acessórios da enunciação.

A compreensão do sentido singular que decorre da articulação das formas mobiliza o elemento central do segundo aspecto da enunciação apontado por Benveniste: considerando que "A enunciação supõe a conversão individual da língua em discurso" (BENVENISTE,
1970/2006, p. 83), cabe investigar "como o 'sentido' se forma em 'palavras" no texto sob avaliação; logo, cabe investigar a semantização da língua. Para isso, é preciso examinar os "procedimentos pelos quais as formas linguísticas da enunciação se diversificam e se engendram" (BENVENISTE, 1970/2006, p. 83). E esse exame leva em conta o texto como ato enunciativo e como discurso, materialidade do ato. Ao falar da semantização, Benveniste refere o artigo Semiologia da língua (1969/2006). Seguimos o mestre e, aqui, também convocamos o que lá o linguista diz a respeito do discurso e da constituição do seu sentido:

Ora, a mensagem não se reduz a uma sucessão de unidades que devem ser identificadas separadamente; não é uma adição de signos que produz o sentido, é, ao contrário, o sentido ("o intencionado") [o intentado], concebido globalmente, que se realiza e se divide em "signos" particulares, que são as PALAVRAS (BENVENISTE, 1969/2006, p. 65).

Por isso, o exame do texto sob avaliação deve considerar a articulação entre o todo do texto como ato (o plano global) e suas partes como discurso (o plano analítico ${ }^{9}$ ), de tal modo que o quinto princípio enunciativo postula que a avaliação de textos acadêmicos considera a inter-relação entre os planos global e analítico do texto. 
Apresentamos, a seguir, uma síntese dos princípios enunciativos formulados nesta seção.

Quadro 1 - Síntese dos princípios enunciativos

Primeiro princípio: a avaliação de textos acadêmicos considera a cultura acadêmica como um conjunto de valores que rege os modos de enunciação no universo acadêmico.

Segundo princípio: a avaliação de textos acadêmicos considera a intersubjetividade constitutiva da conversão da língua em discurso pelo aluno.

Terceiro princípio: a avaliação de textos acadêmicos considera a situação criadora de referência para o aluno expressar sua relação com o mundo.

Quarto princípio: a avaliação de textos acadêmicos considera a imbricação entre forma e sentido resultante da atualização pelo aluno dos índices específicos e dos procedimentos acessórios da enunciação.

Quinto princípio: a avaliação de textos acadêmicos considera a inter-relação entre os planos global e analítico do texto.

Fonte: elaborado pelos autores.

Em nosso entendimento, esse conjunto de fundamentos constitui-se num referencial para o exame e, portanto, para a avaliação do texto acadêmico escrito.

\section{Parâmetros enunciativos para a avaliação de textos acadêmicos escritos}

Nas seções anteriores, com base em alguns postulados benvenistianos, procuramos construir um referencial teórico-metodológico para a avaliação de textos acadêmicos escritos. Tal referencial comporta a concepção enunciativa, as instâncias enunciativas e os princípios enunciativos de avaliação. Entendemos que esses elementos servem como subsídios para o professor desenvolver seus instrumentos de avaliação, que, como tais, serão frutos de uma transposição didática desse referencial que sustenta seu fazer docente. Em outras palavras: não é a teoria enunciativa que será apresentada aos alunos, em sala de aula, mas o deslocamento resultante de uma mediação pedagógica que gera instrumentos de avaliação do texto acadêmico escrito.

Nesta seção, apresentaremos o instrumento avaliativo que elaboramos para a avaliação da produção textual na Universidade: a grade de avaliação. Nossa grade, concebida para ser compartilhada entre todos na sala de aula, constitui-se de quatro parâmetros - interlocução, contexto, texto e linguagem -, que decorrem de uma transposição didática dos princípios enunciativos, conforme o quadro 2 busca ilustrar. 
Quadro 2 - Transposição didática dos princípios enunciativos

\begin{tabular}{|c|c|c|}
\hline \multicolumn{2}{|c|}{$\begin{array}{l}\text { PRINCÍPIOS TEÓRICO-METODOLÓGICOS } \\
\text { PROFESSOR }\end{array}$} & $\begin{array}{l}\text { PARÂMETROS DA GRADE AVALIATIVA } \\
\text { PROFESSOR-ALUNO / ALUNO-ALUNO }\end{array}$ \\
\hline \multirow{5}{*}{ 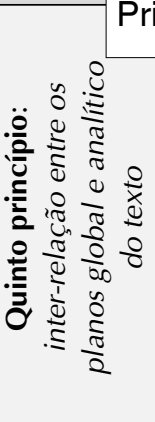 } & Primeiro princípio: cultura acadêmica & \\
\hline & $\begin{array}{l}\text { Segundo princípio: } \\
\text { Ato - (inter)subjetividade }\end{array}$ & Interlocução \\
\hline & Terceiro princípio: & Contexto \\
\hline & Situação & Texto \\
\hline & $\begin{array}{l}\text { Quarto princípio: } \\
\text { Instrumentos }\end{array}$ & Linguagem \\
\hline
\end{tabular}

Fonte: elaborado pelos autores.

De antemão, cabe destacar que os parâmetros propostos não se circunscrevem a um gênero textual específico; trata-se, antes, de aspectos que constatamos transversais à conversão da língua em discurso em variados gêneros acadêmicos e que, por isso mesmo, configuram uma grade genérica o suficiente para ser adaptada, se necessário, a cada gênero a ser trabalhado em sala de aula. Para compreender tal grade, é preciso retomar os princípios enunciativos expostos anteriormente.

O primeiro princípio - a avaliação de textos acadêmicos considera a cultura acadêmica como um conjunto de valores que rege os modos de enunciação no universo acadêmico - engloba e determina os demais. Se a cultura "Consiste numa multidão de noções e de prescrições e também em interdições específicas" (BENVENISTE, 1963/2005, p. 32, grifo do autor), a cultura acadêmica pres- creve e interdita dados usos da língua como mais ou menos apropriados às relações intersubjetivas e às situações enunciativas vivenciadas na universidade. Considerando que, "Pela língua, o homem assimila a cultura, a perpetua ou a transforma" (BENVENISTE, $1963 / 2005$, p. 32), o locutor-avaliador deve observar como o alocutário-avaliado apreende em seu discurso os valores culturais acadêmicos, incorporando-os ou alterando-os. Essa observação passa, necessariamente, pela avaliação integrada dos quatro parâmetros, todos submetidos às representações que dirigem a vida e a atividade humanas no mundo acadêmico.

Já o segundo princípio - a avaliação de textos acadêmicos considera a intersubjetividade constitutiva da conversão da língua em discurso pelo aluno - converte-se no parâmetro interlocução. Aqui, não se trata das 
relações intersubjetivas estruturantes das instâncias de avaliação professor-aluno, aluno-aluno e autoavaliação: trata-se da interlocução projetada na tarefa encaminhada pelo professor. Isso significa que, por um lado, o aluno deve primeiro colocar-se como locutor (eu) do quadro figurativo da tarefa e produzir o seu texto em função do interlocutor delineado nessa tarefa, a fim de realizar com êxito a ação por ela proposta; por outro, o professor ou o colega devem colocar-se como alocutários $(t u)$ do quadro figurativo da tarefa, pois somente assim poderão aferir o desempenho do alocutário-avaliado no atendimento à interlocução prevista. Para avaliar o parâmetro interlocução, consideramos alguns dos índices de intersubjetividade delimitados por Cremonese (2014) para o texto acadêmico, dentre os quais ressaltamos os seguintes: a) o conteúdo informacional, organizado a partir do conhecimento prévio atribuído ao leitor; b) o público-alvo, considerado em termos de restrição ou amplitude; c) a seleção bibliográfica, pautada na necessidade de convocar referências para legitimar o dizer junto ao interlocutor.

Por sua vez, o terceiro princípio - $a$ avaliação de textos acadêmicos considera a situação criadora de referência para o aluno expressar sua relação com o mundo - converte-se nos parâmetros contexto e texto. A avaliação do parâmetro contexto deve contemplar as três dimensões da referência destacadas por Oliveira (2016) na teorização benvenistiana ${ }^{10}$ : a) a $s i$ tuação discursiva, que cria a referência e, ao mesmo tempo, é recriada por ela a cada ato enunciativo, fornecendo as condições de produção e compreensão do discurso (quem fala? Para quem? Onde? Quando? Sobre o quê? Por quê?); b) o tema do discurso, que consiste no objeto da alocução referido e co-referido por eu e $t u$ e que exige de ambos a mobilização dos conhecimentos disciplinares de seus campos do saber; c) a atitude do locutor em relação ao que diz e a quem diz, que se traduz no propósito de seu texto e que comanda todas as suas escolhas de forma, sentido e conteúdo. Além desses aspectos, a adequação às situações de uso da língua na Universidade supõe outros que devem ser avaliados no parâmetro contexto, como o contexto social mais amplo e o veículo de circulação do texto, cujas coerções também regulam os modos de enunciação.

$\mathrm{O}$ atendimento ao gênero acadêmico solicitado pela tarefa, ainda que possa ser considerado uma característica da adequação contextual, em nossa grade é avaliado no parâmetro texto. Conforme Motta-Roth e Hendges (2010, p. 25), “o primeiro passo para produzir um texto acadêmico é verificar quais os gêneros mais usados na área em questão e como esses gêneros se configuram". A configuração desses gêneros, contudo, pode variar não só de uma área para outra como também de uma situação enunciativa para outra, pois, se o locutor, para compartilhar sua experiência e ter 
acesso à do outro, precisa se apropriar do aparato simbólico que une homem, língua e cultura, essa apropriação também está sujeita ao ineditismo da enunciação. Isso demanda do locutor-avaliador certa sensibilidade para analisar a atualização da regularidade do gênero na singularidade de cada texto. Em outras palavras, o aluno pode expressar sua relação com o mundo acadêmico tanto correspondendo às expectativas culturais desse quanto ao gênero em foco como subvertendo-as para produzir efeitos de sentido adequados à interlocução e ao contexto.

O quarto princípio - a avaliação de textos acadêmicos considera a imbricação entre forma e sentido resultante da atualização pelo aluno dos índices específicos e dos procedimentos acessórios da enunciação - converte-se no parâmetro linguagem. Esse parâmetro avalia o uso dos recursos linguísticos empregados pelo locutor para "influenciar de algum modo o comportamento do alocutário" (BENVENISTE, 1970/2006, p. 86): recursos de paragrafação, referenciação, sequenciação, modalização, adequação lexical e gramatical, enfim, a diversificação e o engendramento das formas (sintagmatização) a serviço da produção dos sentidos (semantização).

Por fim, o quinto princípio - $a$ avaliação de textos acadêmicos considera a inter-relação entre os planos global e analítico do texto - não se converte em nenhum parâmetro da grade de avaliação: enquanto o primeiro princípio tem natureza englobante, porque relacionado aos efeitos da cultura sobre a interlocução, o contexto, o texto e a linguagem, esse último princípio tem natureza operacional, pois diz respeito ao modo como o avaliador examina o texto, isto é, ao modo como a leitura se instancia, em um movimento articulado entre o todo do texto e suas partes, levando em conta todos os parâmetros da grade.

Convém observar que os planos global e analítico referidos acima (termos do campo da enunciação) não correspondem aos procedimentos holístico e analítico (termos do campo da avaliação): enquanto estes dizem respeito à avaliação educacional, aqueles se referem à análise enunciativa da linguagem, não circunscrita ao contexto de ensino-aprendizagem. De acordo com Dilli, Schoffen e Schlatter (2012), o procedimento holístico consiste na atribuição de uma única nota ao texto a partir de uma avaliação integrada dos parâmetros, ao passo em que o procedimento analítico pontua separadamente cada um dos aspectos avaliados. Como não pontuamos os parâmetros separadamente, nossa grade é holística e não analítica, mas implica um exame dos planos global e analítico do texto, pois analítico, em plano analítico, não se confunde com analítico, em avaliação analítica; tais termos estão em relação não de sinonímia, mas de homonímia, apresentando a mesma forma, porém sentidos diferentes. Segundo as autoras, a adoção de uma avaliação 
holística é mais coerente com uma perspectiva de ensino-aprendizagem orientada pelo uso da linguagem, na medida em que

Esse procedimento reflete reações autênticas e pessoais de leitores, direcionando a leitura para o que o escritor foi capaz de fazer e não para os pontos fracos de um texto. Nesse sentido, reproduz, ainda que parcialmente, a relação que um leitor em geral tem com o texto em situações de leitura na vida cotidiana, ou seja, sabemos dizer se um texto está adequado/bom/cumprindo seu objetivo (ou não) porque levamos em conta todos os aspectos que o compõem face à interlocução e propósito projetados e à nossa experiência anterior com essas práticas letradas. Muita atenção a aspectos específicos de uma produção textual, como em escalas analíticas, poderia obscurecer o sentido do todo (DILLI; SCHOFFEN; SCHLATTER, 2012, p. 180, grifos nossos).

Nossa grade holística, em parte inspirada na proposta por Simões et al. (2012, p. 130-131), apresenta a seguinte configuração: na primeira coluna da esquerda, constam os quatro parâmetros avaliativos - interlocução, contexto, texto e linguagem -, cada qual sintetizado por uma questão que deve nortear a leitura do respectivo parâmetro a ser feita pelo avaliador. Nas três outras colunas, são apresentados os três níveis de desempenho - atingido, atingido parcialmente $\mathrm{e}$ não atingido - e os respectivos descritores de cada nível. Na base da grade, há um espaço reservado a comentários, no qual o avaliador pode registrar comentários gerais sobre o texto, bem como comentários pontuais sobre um ou mais descritores de um parâmetro específico.
Tais comentários podem incluir tanto elogios a aspectos positivos do texto como recomendações para reescrita de trechos com inadequações de forma e/ ou sentido. $\mathrm{O}$ avaliador pode assinalar essas inadequações nos descritores circulando-as, sublinhando-as, destacando-as com caneta marca-texto ou, se preferir trabalhar com a grade no computador e depois imprimi-la ou encaminhá-la ao aluno por meio de plataformas digitais como o Moodle -, pode ainda se valer de outros recursos de edição de texto, como o negrito. A marcação de descritores específicos deve-se ao fato de que nem sempre o texto avaliado se encaixará em todos os descritores de um mesmo nível de desempenho.

O espaço para comentários vai ao encontro do que diz Normand (2009) sobre a análise semântica associar sempre "uma análise semiótica do enunciado a um comentário sobre a situação cada vez particular da enunciação (tal sujeito, tal tempo, tal referente, tal interação [...]); assim como todo comentário de texto, essa análise interpreta os enunciados, mas não pretende dizer tudo sobre seu sentido" (NORMAND, 2009, p. 182). Os comentários ao fim da grade, portanto, não buscam fazer um parecer exaustivo de todos os aspectos do texto, mas uma observação daqueles mais relevantes para a construção dos sentidos, para a realização da tarefa proposta e para o que está sendo foco de ensino-aprendizagem no momento. 
Os parâmetros que compõem a grade abaixo são nela apresentados separadamente apenas para fins didáticos, pois, assim como os princípios teórico-metodológicos dos quais resultam, são quesitos que se recobrem tanto empírica quanto teoricamente. Não há como avaliar o atendimento de um texto à interlocução projetada na tarefa dissociadamente da sua adequação ao contexto proposto e ao gênero solicitado; tampouco se podem avaliar tais dimensões textuais e contextuais sem levar em conta como essas repercutem nas dimensões lexicais e gramaticais e vice-versa. Isso porque o funcionamento intersubjetivo e referencial do discurso não se dissocia do seu funcionamento linguístico. Esse imbricamento das dimensões estruturantes do texto atesta a transversalidade enunciativa, defendida por Flores (2011) e ligada ao fato de a enunciação não ser um nível a mais da análise linguística, algo que se acrescenta à morfologia, à sintaxe, à semântica e à pragmática, mas um ponto de vista de análise cujo núcleo é o sentido e

[...] que incide em cada um dos níveis separadamente e/ou em inter-relação. Assim, a enunciação é, em nossa perspectiva, sempre transversal e nunca linear. Esse é seu lugar metodológico (FLORES, 2011, p. 402).
Desse modo, embora o parâmetro contexto, por exemplo, contemple o quadro enunciativo eu-tu-ele-aqui-agora e, portanto, inclua locutor e alocutário, para fins de avaliação, reservamos o exame da relação intersubjetiva ao parâmetro interlocução. $\mathrm{O}$ mesmo acontece com os demais parâmetros, o que nos levou a optar sempre pelo que julgamos mais essencial em cada parâmetro, caso contrário avaliaríamos mais de uma vez um mesmo aspecto.

Feitos esses apontamentos, passemos, pois, à grade. 


\begin{tabular}{|c|c|c|c|}
\hline & ATINGIDO & ATINGIDO PARCIALMENTE & NÃO ATINGIDO \\
\hline $\begin{array}{l}\text { INTERLOCUÇÃO } \\
\text { O texto pressupõe } \\
\text { a existência do in- } \\
\text { terlocutor delinea- } \\
\text { do na tarefa? }\end{array}$ & $\begin{array}{l}\text { 1) Seleciona, organiza e relaciona } \\
\text { informações com base no grau } \\
\text { de conhecimento prévio sobre } \\
\text { o tema atribuído ao interlocutor } \\
\text { projetado. } \\
\text { 2) Considera o público-alvo do } \\
\text { veículo de circulação do texto, se } \\
\text { mais restrito ou mais amplo. } \\
\text { 3) Mobiliza referências acadêmi- } \\
\text { cas, via recursos de citação, para } \\
\text { legitimar seu dizer e convocar o in- } \\
\text { terlocutor a confiar no que é dito. }\end{array}$ & $\begin{array}{l}\text { 1) O conteúdo informacional pres- } \\
\text { supõe um interlocutor, mas sua } \\
\text { organização no texto precisa ser re- } \\
\text { pensada considerando-se o conhe- } \\
\text { cimento prévio desse interlocutor. } \\
\text { 2) Considera o veículo de circu- } \\
\text { lação do texto, mas não o perfil } \\
\text { específico de seu público-alvo OU } \\
\text { considera o perfil de um público- } \\
\text {-alvo não ligado a um veículo de } \\
\text { circulação específico. } \\
\text { 3) Há mobilização de referências } \\
\text { acadêmicas, mas a sua pertinência } \\
\text { precisa ser repensada consideran- } \\
\text { do-se o posicionamento defendido } \\
\text { no texto E/OU há mobilização de } \\
\text { referências acadêmicas pertinentes, } \\
\text { mas a articulação das citaçães preci- } \\
\text { sa ser repensada considerando-se o } \\
\text { posicionamento defendido no texto. }\end{array}$ & $\begin{array}{l}\text { 1) Não pressupõe a } \\
\text { existência de um inter- } \\
\text { locutor OU pressupõe } \\
\text { outro interlocutor que } \\
\text { não o delineado na } \\
\text { tarefa. }\end{array}$ \\
\hline $\begin{array}{l}\text { CONTEXTO } \\
\text { O texto contempla } \\
\text { os contextos social } \\
\text { e enunciativo defi- } \\
\text { nidos na tarefa? }\end{array}$ & $\begin{array}{l}\text { 1) Considera o contexto social } \\
\text { amplo e o veículo de circulação } \\
\text { do texto. } \\
\text { 2) Aborda o tema proposto pela } \\
\text { tarefa, constituindo um posicio- } \\
\text { namento crítico e autoral. } \\
\text { 3) Cumpre o propósito definido na } \\
\text { tarefa, considerando o interlocutor } \\
\text { delineado e os recursos linguísti- } \\
\text { cos necessários para estabelecer a } \\
\text { interlocução. }\end{array}$ & $\begin{array}{l}\text { 1) Considera o contexto social } \\
\text { amplo, mas não a especificidade } \\
\text { do veículo de circulação do texto. } \\
\text { 2) Demonstra pouca criticidade e } \\
\text { autoria na abordagem do tema E/ } \\
\text { OU tangencia o tema. } \\
\text { 3) Cumpre, de modo geral, o } \\
\text { propósito definido na tarefa, mas } \\
\text { apresenta dificuldades no encami- } \\
\text { nhamento dado a esse propósito ao } \\
\text { longo do texto. }\end{array}$ & $\begin{array}{l}\text { 1) Foge completamente } \\
\text { ao tema proposto E/OU } \\
\text { não cumpre o propósi- } \\
\text { to definido na tarefa. }\end{array}$ \\
\hline $\begin{array}{l}\text { TEXTO } \\
\text { A organização do } \\
\text { texto corresponde } \\
\text { às expectativas da } \\
\text { cultura acadêmica } \\
\text { quanto ao gênero a } \\
\text { que pertence? }\end{array}$ & $\begin{array}{l}\text { 1) O texto apresenta as carac- } \\
\text { terísticas do gênero acadêmico } \\
\text { solicitado pela tarefa, incluindo } \\
\text { o atendimento às normas gerais } \\
\text { de formatação da escrita acadê- } \\
\text { mica e às específicas da tarefa em } \\
\text { questão. } \\
\text { 2) As subversões em relação às ca- } \\
\text { racterísticas do gênero, se existen- } \\
\text { tes, OU não comprometem a acei- } \\
\text { tação do texto como pertencente } \\
\text { ao gênero em questão OU são } \\
\text { reconhecíveis como produtoras } \\
\text { de efeitos de sentido adequados à } \\
\text { interlocução e ao contexto. }\end{array}$ & $\begin{array}{l}\text { 1) O texto atende, de modo geral, } \\
\text { ao gênero acadêmico solicitado } \\
\text { pela tarefa, mas apresenta algumas } \\
\text { inadequações relativas a uma ou } \\
\text { mais características desse gênero } \\
\text { E/OU às normas gerais de forma- } \\
\text { tação da escrita acadêmica E/OU } \\
\text { às normas específicas da tarefa em } \\
\text { questão. }\end{array}$ & $\begin{array}{l}\text { 1) } \mathrm{O} \text { texto não atende } \\
\text { ao gênero acadêmico } \\
\text { solicitado pela tarefa } \mathrm{E} / \\
\text { OU às normas gerais de } \\
\text { formatação da escrita } \\
\text { acadêmica E/OU às } \\
\text { normas específicas da } \\
\text { tarefa em questão. }\end{array}$ \\
\hline
\end{tabular}


cont.

\begin{tabular}{|c|c|c|c|}
\hline $\begin{array}{l}\text { LINGUAGEM } \\
\text { Os recursos linguís- } \\
\text { ticos são emprega- } \\
\text { dos para produzir } \\
\text { efeitos de sentido } \\
\text { adequados à inter- } \\
\text { locução, ao con- } \\
\text { texto e ao gênero } \\
\text { acadêmico defini- } \\
\text { dos na tarefa? }\end{array}$ & $\begin{array}{l}\text { 1) Os parágrafos estabelecem re- } \\
\text { lações de sentido adequadas tanto } \\
\text { na sua estrutura interna quanto na } \\
\text { transição entre eles. } \\
\text { 2) As cadeias referenciais e se- } \\
\text { quenciais são bem construídas. } \\
\text { 3) Há um uso variado de nexos } \\
\text { e modalizadores, que produzem } \\
\text { efeitos de sentido apropriados à } \\
\text { interlocução, ao contexto e ao } \\
\text { gênero acadêmico. } \\
\text { 4) O vocabulário empregado re- } \\
\text { vela um repertório lexical variado } \\
\text { e adequado ao tema do texto e ao } \\
\text { respectivo campo do saber. } \\
\text { 5) Inadequações linguísticas pon- } \\
\text { tuais (pontuação, ortografia, re- } \\
\text { gência, concordância etc.) não } \\
\text { prejudicam a construção de sen- } \\
\text { tidos no texto. }\end{array}$ & $\begin{array}{l}\text { 1) Os parágrafos estabelecem } \\
\text { relações de sentido adequadas } \\
\text { na sua estrutura interna, mas não } \\
\text { na transição entre eles OU não } \\
\text { estabelecem relações de sentido } \\
\text { adequadas na sua estrutura interna. } \\
\text { 2) Há problemas de referenciação } \\
\text { E/OU de sequenciação que preju- } \\
\text { dicam a coesão textual. } \\
\text { 3) Há um uso pouco diversificado } \\
\text { de nexos e modalizadores, mas } \\
\text { isso não impede a produção de } \\
\text { efeitos de sentido apropriados à } \\
\text { interlocução, ao contexto e ao } \\
\text { gênero acadêmico. } \\
\text { 4) O vocabulário empregado é re- } \\
\text { lativamente diversificado e coeren- } \\
\text { te com o tema abordado no texto e } \\
\text { o respectivo campo do saber. } \\
\text { 5) Inadequações linguísticas recor- } \\
\text { rentes revelam domínio mediano } \\
\text { da modalidade escrita e do registro } \\
\text { formal da língua, prejudicando par- } \\
\text { cialmente a construção de sentidos } \\
\text { no texto. }\end{array}$ & $\begin{array}{l}\text { 1) Os parágrafos não } \\
\text { apresentam uma or- } \\
\text { ganização adequada } \\
\text { tanto na sua estrutura } \\
\text { interna quanto na tran- } \\
\text { sição entre eles. } \\
\text { 2) As cadeias referen- } \\
\text { ciais e sequenciais não } \\
\text { são bem construídas, } \\
\text { prejudicando a cons- } \\
\text { trução de sentidos no } \\
\text { texto. } \\
\text { 3) Há um uso precário } \\
\text { de nexos e modaliza- } \\
\text { dores, que produzem } \\
\text { efeitos de sentido pou- } \\
\text { co ou não apropria- } \\
\text { dos à interlocução, ao } \\
\text { contexto e ao gênero } \\
\text { acadêmico. } \\
\text { 4) O vocabulário em- } \\
\text { pregado é pouco diver- } \\
\text { sificado e inadequado } \\
\text { ao tema abordado no } \\
\text { texto e ao respectivo } \\
\text { campo do saber. } \\
\text { 5) As excessivas ina- } \\
\text { dequações linguísticas } \\
\text { comprometem a cons- } \\
\text { trução de sentidos no } \\
\text { texto e a realização da } \\
\text { tarefa proposta. }\end{array}$ \\
\hline \multicolumn{4}{|l|}{ COMENTÁRIOS: } \\
\hline
\end{tabular}

Fonte: elaborado pelos autores.

Vale ressaltar ainda a importância de o professor compartilhar com alunos parâmetros anteriormente citados, esclarecendo-os a esses durante todo o processo de ensino-aprendizagem - e não só na entrega da grade junto do texto avaliado -, processo do qual a avaliação é parte integrante e, por isso mesmo, uma prática contínua, não restrita ao término de uma tarefa isolada, mas integrada a todas as atividades desenvolvidas ao longo do período letivo. A socialização dos parâmetros com os discentes requer do docente um gesto de abertura, que possibilite negociações e ajustes da grade, conforme as demandas de cada grupo e 
também de cada tarefa. Essa socialização contribui para que a avaliação de textos acadêmicos deixe de ser uma prática institucional do mistério (LILLIS, 1999), uma vez que o aluno se torna consciente do que representa cada um dos parâmetros a partir dos quais suas produções devem ser avaliadas pelo outro (nas instâncias de avaliação professor-aluno e aluno-aluno) e por si próprio (na instância de autoavaliação), o que lhe permite a busca por adequar seus textos a tais parâmetros desde a primeira versão, e não apenas na reescrita.

Esse modo de avaliar o texto acadêmico está orientado numa direção: a da reescrita. Como bem salientam Simões et al. (2012), a reescrita é inerente ao ato de escrever e implica um retorno ao dizer para verificar se, de fato, conseguiu-se cumprir com o propósito da interlocução: "Ou será que falta algo, sobra algo, há algo obscuro ou mal realizado?" (SIMÕES et al., 2012, p. 174). Na primeira coluna de nossa grade, as perguntas que sintetizam cada parâmetro orientam para essa concepção de reescrita como "resultado de uma leitura conceitual do texto", o que "[...] não se confunde com a pura e simples revisão final de um texto, que incide sobre detalhes mais miúdos" (SIMÕES et al., 2012, p. 174). Num viés enunciativo,

A re-escrita funciona, assim, como um re-torno: um retorno ao seu lugar de locutor, mas, dessa vez, a um lugar de enunciação reconfigurado, uma vez reconfigurada a estrutura enunciativa (JUCHEM, 2012, p. 126, grifos da autora).
Ao final desse processo de escrita, reescrita e revisão textual, a atribuição de um conceito ou de uma nota pelo professor ao texto - em atendimento às exigências formais da Universidade representará não um fim em si mesma, mas um ponto de chegada no desenvolvimento da competência discursiva do aluno.

Por isso, entendemos que a avaliação do texto acadêmico escrito pautada por uma grade holística geral, que representa uma possibilidade de transposição didática de princípios enunciativos, configura uma perspectiva que leva em conta menos a regularidade e mais a singularidade do processo de produção textual acadêmica e das relações intersubjetivas que o constituem. Ora, a característica genérica de nossa grade de avaliação holística decorre da transversalidade de aspectos relativos à conversão da língua em discurso no texto acadêmico. Para além disso, há ainda, propositalmente, o desejo de produzi-la dessa maneira: não focada nos elementos que caracterizam formalmente um gênero acadêmico, o que remeteria às suas regularidades, a grade prima pelo exame da singularidade como cada escrevente se constitui por meio das relações intersubjetivas na escrita, relações que, por sua vez, convocam aspectos ligados à regularidade dos gêneros, mas não se encerram nela. 
No entanto, frisamos que, se o professor julgar pertinente, poderá adaptar os parâmetros interlocução, contexto, texto e linguagem a cada gênero e neles inserir descritores que se refiram às especificidades do gênero em questão, sem perder de vista a percepção da singularidade como cada aluno se constitui como sujeito de linguagem na cultura acadêmica ao manejar os textos próprios a esse espaço. Além disso, o professor pode ainda, se preferir, produzir uma versão reduzida dessa grade de referência, fazendo com que o aluno tenha de recorrer a essa para compreender os apontamentos naquela.

\section{Conclusão}

Este trabalho partiu de uma constatação: a de que a avaliação da produção textual na Universidade é, de um lado, objeto pouco investigado e, de outro, aspecto ainda velado em sala aula. E é para ambos os lados, a pesquisa e a docência, que julgamos que este estudo apresenta contribuições.

Primeiro, ao estabelecer como ponto de vista teórico-metodológico a reflexão enunciativa de Émile Benveniste e compreender que a intersubjetividade possibilita a enunciação - uma vez que "Cada locutor não pode propor-se como sujeito sem implicar o outro [...]" (BENVENISTE, 1963/2005, p. 26) -, concebemos a avaliação como um ato enunciativo que atua na direção de ressignificar os modos de enunciação pelos quais o aluno converte a língua em discurso e faz a passagem de locutor a sujeito no espaço acadêmico. Essa concepção, que convoca o quadro figurativo da enunciação, foi por nós desdobrada em instâncias avaliativas: a instância de avaliação professor-aluno, a instância de avaliação aluno-aluno e a instância de autoavaliação. Tais instâncias, articuladas a um conjunto de princípios enunciativos, permitiram-nos propor uma perspectiva de avaliação de textos acadêmicos escritos que leva em conta menos a regularidade e mais a singularidade do processo de produção textual acadêmica e das relações intersubjetivas que o constituem, porque atenta ao modo como cada aluno, na relação com o outro e com a cultura, apropria-se dos conhecimentos disciplinares e das convenções escriturais de seu campo do saber e os materializa em seu texto.

Segundo, ao propor uma grade de avaliação de textos acadêmicos escritos a partir desse construto, buscamos contribuir tanto para o ensino como para a aprendizagem de língua materna na universidade: para o ensino, ao fornecer subsídios teórico-metodológicos para a prática pedagógica do professor; para a aprendizagem, ao incluir o aluno como participante ativo do processo avaliativo. Nossa proposta alinha-se, assim, ao paradigma emergente de avaliação, privilegiando uma avaliação formativa, processual e diagnóstica, vista não como um ponto definitivo de chegada, mas como uma pausa para recuperar 
o fôlego e retomar a marcha de forma mais adequada (LUCKESI, 1996). Em outras palavras, a avaliação é entendida, aqui, não como um fim em si mesma, mas como um meio de refletir sobre os caminhos já percorridos e de tomar decisões em relação àqueles por percorrer. Tal abordagem também contribui para o exercício da avaliação como uma experiência coletiva e democrática, ao torná-la uma prática socializada e compartilhada por professor e alunos.

A dupla contribuição esperada por esse estudo reflete a nossa própria condição como professores-pesquisadores, comprometidos tanto com a investigação da relação sempre fascinante entre o homem e a linguagem quanto com a busca por respostas aos desafios impostos pela sala de aula. Se as concepções teóricas assumidas pelo docente são definidoras da sua prática de ensino, cremos que tais concepções definem também a sua prática avaliativa, o que evidencia a necessidade e a importância de o professor ter 0 seu fazer respaldado por um referencial teórico que não ignore a complexidade e o dinamismo de "todas as realizações individuais e coletivas que estão ligadas ao exercício do discurso" (BENVENISTE, 1966/2006, p. 222).

\section{L'évaluation de textes universitaires écrits : une perspective énonciative}

\section{Résumé}

Ce travail vise à proposer une perspective énonciative d'évaluation de textes universitaires écrits en contexte d'enseignement-apprentissage de langue maternelle à l'Université. Dans un premier moment, à partir de présupposés de la Théorie de l'Énonciation d'Émile Benveniste, on présente : a) une conception d'évaluation comme un acte d'énonciation ; b) le fonctionnement énonciatif des instances d'évaluation enseignant-apprenant, apprenant-apprenant et auto-évaluation ; c) des principes théorico-méthodologiques pour l'évaluation qui considèrent la culture, l'intersubjectivité, la situation créatrice de référence, les instruments linguistiques de réalisation de l'énonciation et les plans global et analytique d'analyse énonciative du texte. Dans un deuxième moment, à partir de ces éléments-là, on propose une grille d'évaluation du texte universitaire écrit.

Mots-clés : Évaluation. Énonciation. Écriture universitaire.

\section{Notas}

1 O homem na língua é, inclusive, o título que o próprio Benveniste dá à quinta parte dos Problemas de Linguística Geral I e II.

2 Para uma reflexão mais aprofundada sobre o conceito de posição de locutor, consultar Knack (2016b).

3 Tal concepção inscreve-se numa proposta mais ampla de Oliveira (2016), que busca lançar as bases para um diálogo entre a Teoria da Enunciação de Émile Benveniste e os Estudos dos Letramentos Acadêmicos, a partir da 
proposição de concepções e princípios para um modelo enunciativo de letramento acadêmico.

4 Aideia de "enunciação de retorno" parte do próprio uso desse termo por Benveniste: "Antes da enunciação, a língua não é senão possibilidade da língua. Depois da enunciação, a língua é efetuada em uma instância de discurso, que emana de um locutor, forma sonora [ou escrita] que atinge um ouvinte [ou leitor] e que suscita uma outra enunciação de retorno." (BENVENISTE, 1970/2006, p. 83-84, acréscimos nossos).

5 Embora não ignoremos o fato de que a avaliação educacional, na perspectiva formativa, é uma experiência coletiva que implica outros partícipes do processo educacional além do professor e dos alunos, restringimos nossa abordagem a esses atores.

6 Tal transcendência do $e u$ em relação ao $t u$, sendo uma característica definidora da própria enunciação, não se circunscreve a esta primeira instância, estendendo-se às demais; se a destacamos aqui, é para reforçar a assimetria da relação professor-aluno.

7 O termo locutor, em "eu locutor", não tem estatuto teórico, como tem nas ocorrências em que designa o indivíduo que se apropria da língua para transformá-la em discurso: locutor pode ser compreendido, aqui, como falante, de maneira que tomamos o eu locutor, nessa acepção, como eu falante, em oposição ao eu ouvinte, a fim de podermos adaptar esses termos ao quadro figurativo da autoavaliação do texto escrito.

8 O termo falante, na proposta de Farias (2016), adquire estatuto teórico em relação de interdependência conceitual com o termo analista de linguagem.

$9 \quad$ A exemplo de Knack (2012), o termo analítico é inspirado no uso que Benveniste dele faz no artigo A forma e o sentido na linguagem, quando indica que “o 'sentido' da frase está na totalidade da ideia percebida por uma compreensão global; a 'forma' se obtém pela dissociação analítica do enunciado, processada até as unidades semânticas, as palavras." (BENVENISTE, 1967/2006, p. 232).

10 Para uma reflexão mais aprofundada sobre a noção de referência em Benveniste e sua relação com o letramento acadêmico, ver Oliveira (2016, p. 107-121).

\section{Referências}

BENVENISTE, Émile. Da subjetividade na linguagem (1958). In: . Problemas de

Linguística Geral I. 5. ed. Campinas, SP: Pontes, 2005. p. 284-293.

O aparelho formal da enunciação (1970). In: . Problemas de Linguística Geral II. 2. ed. Campinas, SP: Pontes, 2006. p. 81-90.

Vista d'olhos sobre o desenvolvimento da linguística (1963). In: Problemas de Linguística Geral I. 2. ed. Campinas, SP: Pontes, 2005. p. 19-33.

Semiologia da língua (1969). In: Problemas de Linguística Geral II.

2. ed. Campinas, SP: Pontes, 2006. p. 43-67.

CREMONESE, Lia Emília. Um olhar enunciativo sobre a relação entre leitura e produção textual na universidade. 2014. $154 \mathrm{f}$. Tese (Doutorado em Estudos da Linguagem) - Programa de Pós-Graduação em Letras, Universidade Federal do Rio Grande do Sul, Porto Alegre, 2014.

DILLI, Camila; SCHOFFEN, Juliana Roquele; SCHLATTER, Margarete. Parâmetros para a avaliação de produção escrita orientados pela noção de gênero do discurso. In: SCHOFFEN, Juliana Roquele et al. (Org.). Português como língua adicional: reflexões para a prática docente. Porto Alegre: Bem Brasil, 2012. p. 171-199.

FARIAS, Bruna Sommer. Os lugares de falante e analista de linguagem e a imbricação das instâncias linguística e antropológica na enunciação. In: SILVA, Silvana; CAVALHEIRO, Juciane (Org.). Atualidade dos estudos enunciativos. Curitiba: Primas, 2016. p. 95-118. 
FLORES, Valdir do Nascimento. A enunciação e os níveis da análise linguística. In: SEMINÁRIO INTERNACIONAL DE TEXTO, ENUNCIAÇÃO E DISCURSO, 2011. Anais... Porto Alegre: EdiPUCRS, 2011. p. 396-402.

. Introdução à teoria enunciativa de Émile Benveniste. São Paulo: Parábola, 2013.

Notas para uma (re)leitura da teoria enunciativa de Émile Benveniste. In: TEIXEIRA, Marlene; FLORES, Valdir do Nascimento (Org.). O sentido na linguagem: uma homenagem à professora Leci Borges Barbisan. Porto Alegre: EdiPUCRS, 2012. p. 149-165.

FLORES, Valdir do Nascimento et al. Enunciação e gramática. São Paulo: Contexto, 2008.

FURTOSO, Viviane Aparecida Bagio. Interface entre avaliação e ensino-aprendizagem: desafios na formação de professores. In: DURÃO, Adja Balbino de Amorim Barbieri; ANDRADE, Otávio Goes; REIS, Simone (Org.). Reflexões sobre o ensino das línguas estrangeiras. Londrina: UEL, 2008. p. 127158.

JUCHEM, Aline. Por uma concepção enunciativa da escrita e re-escrita de textos em sala de aula: os horizontes de um hífen. 2012. 194 f. Dissertação (Mestrado em Estudos da Linguagem) - Programam de Pós-Graduação em Letras, Universidade Federal do Rio Grande do Sul, Porto Alegre, 2012.

KNACK, Carolina. A conversão da língua em discurso no contexto acadêmico e a experiência da significação. Revista Entrelinhas, São Leopoldo, v. 10, n. 1, p. 88-107, jan./jun. 2016a.

. Por uma dimensão antropológica do discurso: as passagens do aluno nas instâncias de ensino. 2016. 164 f. Tese (Doutorado em Estudos da Linguagem) - Programa de Pós-Graduação em Letras, Universidade Federal do Rio Grande do Sul, Porto Alegre, 2016b.
Texto e enunciação: as modalidades falada e escrita como instâncias de investigação. 2012. 189 f. Dissertação (Mestrado em Estudos da Linguagem) - Programa de Pós-Graduação em Letras, Universidade Federal do Rio Grande do Sul, Porto Alegre, 2012.

LILLIS, Theresa. Whose "Common Sense?" Essayist literacy and the institutional practice of mystery. In: JONES, Carys; TURNER, Joan; STREET, Brian (Org.). Students writing in the university: cultural and epistemological issues. Amsterdam: John Benjamins, 1999. p. 127-147.

LUCKESI, Cipriano. Avaliação educacional escolar: para além do autoritarismo. In: . Avaliação da aprendizagem escolar. São Paulo: Cortez, 1996. p. 27-47.

MOTTA-ROTH, Désirée; HENDGES, Graciela M. Produção textual na universidade. São Paulo: Parábola, 2010.

NAUJORKS, Jane da Costa. Leitura e enunciação: princípios para uma análise do sentido na linguagem. 2011. $153 \mathrm{f}$. Tese (Doutorado em Estudos da Linguagem) Programa de Pós-Graduação em Letras, Universidade Federal do Rio Grande do Sul, Porto Alegre, 2011.

NORMAND, Claudine. Os termos da enunciação em Benveniste. In: OLIVEIRA, Sérgio L.; PARLATO, Erika M.; RABELLO, Silvana. $O$ falar da linguagem. São Paulo: Lovise, 1996. p. 127-152.

Semiologia, semiótica, semântica: observações sobre o emprego desses termos por Émile Benveniste. In: NORMAND, Claudine; FLORES, Valdir do Nascimento; BARBISAN, Leci B. (Org.). Convite à Linguística. São Paulo: Contexto, 2009. p. 173-183.

OLIVEIRA, Giovane Fernandes. Do homem na língua ao sujeito na escrita: bases para um diálogo entre Letramento e Enunciação. 2016. 143 f. Trabalho de Conclusão de Curso (Licenciatura em Letras) - Instituto de Letras, Universidade Federal do Rio Grande do Sul, Porto Alegre, 2016. 
SILVA, Carmem Luci da Costa. O homem na cultura reinventando a língua: aquisição e letramento. In: TOLDO, Claudia; STURM, Luciane. Letramento: práticas de leitura e escrita. São Paulo: Pontes, 2015. p. 11-35.

SIMÕES, Luciene Juliano et al. Leitura e autoria: planejamento em Língua Portuguesa e Literatura. Erechim: Edelbra, 2012.

SUASSUNA, Lívia. Paradigmas de avaliação: uma visão panorâmica. In: MARCUSCHI, Elizabeth; SUASSUNA, Lívia (Org.). Avaliação em língua portuguesa: contribuições para a prática pedagógica. Belo Horizonte: Autêntica, 2006. p. 27-47. 